\title{
Koç Spermasının Dondurulmasında Bireysel Farklılıkların Etkisi
}

\author{
Çiğdem ÇEBi ŞEN ${ }^{1 *}$, Recai KULAKSIZ², Ali DAŞKIN³, Ergun AKÇAY ${ }^{3}$ \\ ${ }^{1}$ Harran Üniversitesi, Veteriner Fakültesi, Dölerme ve Suni Tohumlama Anabilim Dalı, Şanlıurfa, Türkiye. \\ ${ }^{2}$ Balıkesir Üniversitesi, Veteriner Fakültesi, Dölerme ve Suni Tohumlama Anabilim Dalı, Balıkesir, Türkiye. \\ ${ }^{3}$ Ankara Üniversitesi, Veteriner Fakültesi, Dölerme ve Suni Tohumlama Anabilim Dalı, Ankara, Türkiye.
}

Geliş Tarihi: 15.02.2017

Kabul Tarihi: 20.04.2017

\begin{abstract}
Özet: Bu çalışma, koç spermasının dondurulmasında bireysel farklııkları ortaya koymak ve bu farklııı üzerine sulandırıcı etkisini belirlemek amacıyla yapıldı. Ejakulatlar 5 Karayaka koçundan sezon içi dönemde suni vajina yardımıyla haftada bir kez alındı. Sperma örnekleri bireysel olarak 4 farklı sperma sulandırııısı (Yağsız süt tozu, Tris, Andromed, Bioxcell) ile sulandırıldı. Sulandırılmış sperma örneklerini içeren payetler $+4{ }^{\circ} \mathrm{C}^{\prime}$ de 2 saat süreyle ekilibre edildikten sonra sIVı azot buharında $\left(-120^{\circ} \mathrm{C}\right) 15$ dakika süreyle donduruldu ve sıvı azot $\left(-196^{\circ} \mathrm{C}\right)$ içinde saklandı. Tüm gruplardaki payetler $37^{\circ} \mathrm{C}$ de 30 saniye süreyle çözdürüldü. Her bir koça ait çözdürülmüş sperma örneklerinde spermatozoa motilitesi (\%), canlı spermatozoa (\%) ve anormal spermatozoa (\%) yönünden değerlendirildi. Yağsız süt tozu sulandırıcısı ile dondurulan sperma örneklerinde çözüm sonu daha yüksek motilite elde edilirken, en düşük motilite oranı Bioxcell sulandırıcısından elde edilmiştir. Sonuç olarak, sunulan çalışmada elde edilen in vitro sperma kalitesi bulgularına göre yağsız süt tozu sulandırıcısının diğer sulandııcılardan daha üstün olduğu ve koçlar arası bireysel farkı azalttığı bulunmuştur.
\end{abstract}

Anahtar Kelimeler: Bireysellik, Koç, Sperma, Sulandırıcılar.

\section{Response to Different Semen Extenders of Individual Ram Semen}

\begin{abstract}
This study was conducted to evaluate individual differences in freezing ram sperm and to determine the extenders and individual sperm interaction. The ejaculates were collected from 5 Karayaka rams by artificial vagina twice a week during the breeding season. The each ejaculate was split into 4 equal aliquots and diluted with skimmed milk, Tris, Andromed and Bioxcell extenders. Straws contained semen was equilibrated at $+4{ }^{\circ} \mathrm{C}$ for $2 \mathrm{~h}$ and than frozen in vapor of $(15$ min at $-120^{\circ} \mathrm{C}$ ) liquid nitrogen and stored in liquid nitrogen. Frozen semen was thawed in a water bath at $37{ }^{\circ} \mathrm{C}$ for 30 seconds. In thawed semen, percentages of spermatozoa motility, viability, and abnormal spermatozoa, for each ejaculate were determined. The post-thaw sperm motility was significantly higher in skimmed milk extender post-thaw, while lowest motility rate was obtained from Bioxcell diluent. Consequently, it was found that skimmed milk extender was better than the other extenders and decreased individual differences between rams.
\end{abstract}

Keywords: Extenders, Individuality, Ram, Semen.

\section{Giriş}

Karayaka koyunu, Karadeniz bölgesinde yetiştirilen ve yerli koyun ırkı içinde yer alan yağsız uzun kuyruklu bir ırktır. Koyun ırkları arasında en düşük süt verimine sahip ırk olmasına rağmen et kalitesi oldukça iyidir. Türkiye'de Karayaka ırkının popülasyon büyüklüğü hakkında bilgilerimiz tahminden öteye gitmemektedir. Şimdilik yok olma riski taşımayan bu ırkın yakından izlenmesinin yararlı olacağı düşünülmektedir. Koyunculuk endüstrisinde, gerek ülkemizde gerekse dünyada dondurulmuş koç spermasıyla rutin olarak koyunlarda suni tohumlama yapılmamaktadır. Bunun çeşitli nedenleri olmakla birlikte en önemli nedenlerinden birisi olarak henüz dondurulmuş koç sperması ile suni tohumlama uygulamalarından tatminkar gebelik sonucu elde edilememiş olmasıdır (O'Hara ve ark., 2010). Genel olarak koç spermasının dondurulmasına yönelik yoğun araştırmalar yapılıyor olmasına rağmen koç spermasının başarılı bir şekilde dondurulması her zaman mümkün değildir. Koç sperması dondurma-çözdürme sürecin- de yüksek oranda motilite kaybına ve akrozomal hasara uğramaktadır (Watson, 1995). Koyunlarda donmuş sperma ile suni tohumlama uygulamalarının yapılabilmesi için ön koşul spermanın optimal şekilde dondurulmasıdır (Roca ve ark., 2006). Koç spermasının dondurulmasında tıpkı diğer türlerde olduğu gibi sodyum sitrat, yağsız süt tozu ve tris bazlı sulandırıcılar kullanılmakla birlikte (Holt, 2000), son zamanlarda boğa spermasının dondurulması için geliştirilmiş bazı ticari sperma sulandırıcıları koç spermasının dondurulmasında kullanılmış ve sulandırıcı olarak kullanılabileceğini bildiren araştırmacılar vardır (Kulaksiz ve Daşkın, 2007). Yine aynı araştırmacılar, yumurta sarısındaki bireysel, ırksal ve türsel farklılıklardan dolayı ve ayrıca süt gibi hayvansal orjinli sperma sulandırıcılarının spermanın mikrobiyel kontaminasyonunda risk taşıdığından Andromed ve Bioxcell gibi sentetik sperma sulandırıcılarının kullanılması gerektiğini savunmaktadırlar (Lopez ve ark., 2000; Smith ve ark., 1993). Koç spermasının dondurulmasında 
kullanılan sulandırıcılarla yapılan çalışmalardan elde edilen sonuçlar bireysel farklılıktan dolayı geniş bir varyasyon gösterebilmektedir (Barbas ve Mascarenhas, 2009). Ayrıca çözüm sonu bireysel farklılık üzerine kullanılan sulandırıcılar ile sperma örneklerinin etkileşime girmesi spermanın kompozisyonunu büyük ölçüde değiştirerek spermanın dondurulması üzerine olumsuz etki yapabilir. Geniş bireysel farklılıktan dolayı dondurma ve çözdürme prosedürü teknolojisi hala optimal değildir. Bu yüzden koyunculuk sektöründe dondurulmuş çözdürülmüş sperma örnekleri ile suni tohumlama uygulamalarındaki istikrarlı bir gelişme için, dondurulmuş-çözdürülmüş sperma örneklerinin kalitesini artırmak ve koçlar arasındaki bireysel değişkenliği en aza indirecek dondurma prosedürü geliştirmek gereklidir. Bu yüzden çalışmada koç spermasının dondurulabilirliğinde bireysel ve sulandırıcıların etkileri araştırılmıştır.

\section{Materyal ve Metot}

Çalışmanın hayvan materyalini 2 yaş ve üzerindeki 5 adet Karayaka ırkı koç oluşturdu. Araştırma sırasında kullanılan koçların bakım ve barındırılması koyun padoklarında standart yetiştirme koşullarında yapıldı. Ejakulatlar sperma dondurma denemelerinde (yağsız süt tozu sulandırıcı ile) çözüm sonrası progressive motilitesi en az \%35 olan ve fertilitesi yüksek olarak bilinen koçlardan sun'i vajina yöntemiyle haftada iki kez alınmıştır. Nativ motilitesi $\% 80$ ve üzerinde olan koçların sperması kullanıldı. Her bir koçtan 10'ar ejakulat olmak üzere toplamda 50 ejakulat alındı. Her koçtan elde edilen her bir ejakulat 4 eşit kısma ayrılarak \%10 yumurta sarısı ve $\% 5$ gliserol içeren Tris, süt tozu ve yumurta sarısı içermeyen AndroMed ve Bioxcell sulandırıcısı ile bir tohumlama dozunda $(0,25 \mathrm{ml}) \quad 100 \times 10^{6}$ motil spermatozoa bulunacak şekilde sulandırılarak dozlandı. Spermanın dondurulması için 4 farklı sperma sulandırıcısı kullanıldı.

\section{Sulandırıcı Kompozisyonları:}

Sulandırıcı T: \%10 yumurta sarısı ve $\% 5$ gliserol içeren Tris bazlı sperma sulandırcısı (3.63 g Tris, 0.5 $\mathrm{g}$ fruktoz, $1.99 \mathrm{~g}$ sitrik asit, $100 \mathrm{ml}$ distile su).

Sulandırıcı S: \%10 yumurta sarısı ve \%5 gliserol içeren yağsız süt tozu sulandırıcısı ( $9 \mathrm{gr}$ yağsız süt tozu, $0.9 \mathrm{~g}$ glukoz, $100 \mathrm{ml}$ distile su).

Sulandırıcı A: Andromed ${ }^{\oplus}$ sulandırıcısı (Minitub, Tiefenbach, Germany)

Sulandırıcı B: Bioxcell ${ }^{\circledR}$ sulandırıcısı (IMV technologies, L'Aigle, Franse).
Spermanın Dondurulması: Sulandırmayı takiben spermalar $0.25 \mathrm{ml}$ lik payetlere çekildi ve $+4{ }^{\circ} \mathrm{C}^{\prime}$ de 2 saat ekilibrasyona bırakıldı. Ekilibrasyondan sonra payetler sıvı azot seviyesinin $4 \mathrm{~cm}$ üzerinde $\left(-120^{\circ} \mathrm{C}\right)$ SIVI azot buharında 15 dakikada donduruldu ve SIVI azota daldırılarak saklandı. Dondurulmuş spermalar araştırma tamamlandıktan sonra spermatozoa motilitesi, canlılık, anormal spermatozoa oranı yönüyle değerlendirildi.

Çözüm Sonrası Spermatolojik Değerlendirmeler: Dondurulmuş payetler $37^{\circ} \mathrm{C}^{\prime}$ de 30 saniye süreyle çözdürüldükten sonra $5 \mu \mathrm{l}$ sperma lam üzerine alınarak üzerine lamel kapatıldı ve spermatozoa motilitesi $37{ }^{\circ} \mathrm{C}^{\prime}$ de Isıtma tablalı faz kontrast mikroskopta $X 40^{\prime} ı$ ık büyütmede en az 5 değişik mikroskop sahasında incelendi. Bulunan ortalama değer yüzde (\%) olarak değerlendirildi. Çözdürülmüş spermalardaki canlı spermatozoa oranı supravital boyama tekniğiyle belirlendi. Eosin-nigrosin boyası kullanılarak hazırlanan frotilerde mikroskop yardımıyla X40 büyütmede en az 200 hücre sayılarak canlı spermatozoa oranı yüzde (\%) olarak ifade edildi. Preparatların değerlendirilmesinde baş kısmı tam boya alan spermatozoonlar ölü, yarı boya alanlar ve hiç boya almayan spermatozoonlar ise canlı olarak değerlendirildi. Sperma numunelerindeki anormal spermatozoa oranı ise sıvı fikzasyon yöntemiyle belirlendi. Hancock solüsyonu kullanılarak fikze edilen hücreler lam-lamel arasında bir fazkontrast mikroskop altında incelendi. İmmersiyon objektif (x100 büyütme) altında en az 200 spermatozoonun çeşitli kısımlarının (akrozom, baş, orta kısım ve kuyruk) incelenmesi sonunda anormal yapı gösteren spermatozoa oranı yüzde (\%) olarak belirlendi.

İstatistiki Analiz: Verilerin normallik varsayımlarını karşılayıp karşılamadığı Shapiro-Wilk testi ile, varyansların homojenliği Levene's testi ile değerlendirildi. Normal dağılmayan verilere logaritmik transformasyon uygulandı. Koçların bireysel farklııkları ve sulandırıcıların etkisinı belirlemek için iki yönlü varyans analizi yapıldı. Koç ile sulandırıcı arasında interaksiyon anlamlı olduğunda GLM (General Lineer Model) prosedürleri kapsamında SPSS (16.0) paket programının syntax menüsüne manuel olarak ayrı bir kodlama yazılarak bu interaksiyon değerlendirildi. $\quad \mathrm{P}<0.05$ düzeyi anlamlı olarak kabul edildi. Sonuçlar ortalama \pm standart hata olarak verildi.

\section{Bulgular}

Yağsız süt tozu, Tris, Andromed ve Bioxcell sulandırıcısıyla bireysel olarak dondurulmuş koç spermasında çözüm sonu başlıca spermatolojik 
özellikler Tablo 1, 2 ve 3'te verilmiştir. Koç ve sulandırıcı etkileşiminde; spermatozoa motilitesi, canlı spermatozoa oranı ve normal spermatozoa üzerine etkisine bakıldığı zaman, yağsız süt sulandırıcısı ile dondurulan sperma örneklerinde çözüm sonu daha yüksek motilite elde edilirken, en düşük motilite oranı Bioxcell sulandırıcısından elde edilmiştir. Koç ve farklı sulandırıcı interaksiyonunun spermatolojik özellikler üzerine etkisi Tablo 1, 2 ve 3'te gösterilmiştir. Koçlar arasındaki bireysel dondurulmaya bakıldığında ise koçlar arasında istatiki bir fark elde edilmiştir. Sütlü sulandırıcı ile sperması en iyi donan 2 numaralı koç iken, en kötü donan 4 ve 5 numaralı koçun sperması olmuştur. Tris sulandırıcısı ile en iyi sperması donan 2 numaralı koç iken, Andromed sulandırıcısı ile en iyi donan koç sperması 2-3 numaralı koçtur ve diğer koçlar arasında koç ve sulandırıcı interaksiyonu bakımından fark elde edilmemiştir. Bioxcell sulandırıcısı ile en iyi donan 2 numaralı koç iken en kötü 4 ve 5 numaralı koç olmuştur.

Tablo 1. Farklı sulandırıcılar ile dondurulan koç spermasının motilite değerleri

\begin{tabular}{lccccccc}
\hline & Yağsız süt tozu & Tris & Andromed & Bioxcell & Koç & Sulandırıcı & Etkileşim \\
\hline Koç 1 & $45.83 \pm 4.92^{\mathrm{a}, \mathrm{B}, \mathrm{C}}$ & $29.173 \pm 4.76^{\mathrm{b}, \mathrm{B}}$ & $22.50 \pm 4.18^{\mathrm{b}, \mathrm{B}}$ & $20.83 \pm 4.92^{\mathrm{b}, \mathrm{B}, \mathrm{C}}$ & & & \\
Koç 2 & $67.50 \pm 2.74^{\mathrm{a}, \mathrm{A}}$ & $60.00 \pm 5.48^{\mathrm{a}, \mathrm{A}}$ & $55.00 \pm 3.16^{\mathrm{b}, \mathrm{A}}$ & $43.33 \pm 2.58^{\mathrm{C}, \mathrm{A}}$ & & & \\
Koç 3 & $53.33 \pm 2.58^{\mathrm{a}, \mathrm{C}}$ & $33.33 \pm 2.58^{\mathrm{b}, \mathrm{B}}$ & $47.50 \pm 6.89^{\mathrm{a}, \mathrm{A}}$ & $25.83 \pm 5.85^{\mathrm{b}, \mathrm{C}}$ & & & \\
Koç 4 & $38.33 \pm 5.16^{\mathrm{a}, \mathrm{B}}$ & $30.83 \pm 6.65^{\mathrm{a}, \mathrm{B}}$ & $21.67 \pm 4.08^{\mathrm{b}, \mathrm{B}}$ & $14.17 \pm 3.76^{\mathrm{b}, \mathrm{B}}$ & $\mathrm{P}<0.001$ & $\mathrm{P}<0.001$ & $\mathrm{P}<0.001$ \\
Koç 5 & $45.00 \pm 4.47^{\mathrm{a}, \mathrm{B}}$ & $26.67 \pm 5.16^{\mathrm{b}, \mathrm{B}}$ & $27.50 \pm 5.24^{\mathrm{b}, \mathrm{B}}$ & $14.17 \pm 4.92^{\mathrm{c}, \mathrm{B}}$ & & & \\
\hline
\end{tabular}

$\mathrm{a}, \mathrm{b}, \mathrm{c} ;$; her satırdaki, $\mathrm{A}, \mathrm{B}, \mathrm{C} ;$; her sütundaki farklı üst karakterler istatistiksel olarak farklılığı ifade etmektedir.

Tablo 2. Koç ve sulandırıcı interaksiyonunun canlı spermatozoa oranı üzerine etkisi

\begin{tabular}{|c|c|c|c|c|c|c|c|}
\hline & Yağsız süt tozu & Tris & Andromed & Bioxcell & Koç & Sulandırıcı & Etkileşim \\
\hline Koç 1 & $50.00 \pm 2.4^{a, B}$ & $43.50 \pm 4.0^{\mathrm{a}, \mathrm{c}}$ & $34.83 \pm 4.5^{b, B}$ & $30.50 \pm 3.2^{b, B, C}$ & & & \\
\hline Koç 2 & $73.33 \pm 2.0^{\mathrm{a}, \mathrm{A}}$ & $70.17 \pm 4.4^{\mathrm{a}, \mathrm{A}}$ & $64.83 \pm 5.6^{\mathrm{b}, \mathrm{A}}$ & $53.67 \pm 2.5^{\mathrm{c}, \mathrm{A}}$ & & & \\
\hline Koç 3 & $60.17 \pm 3.6^{a, c}$ & $43.50 \pm 4.5^{b, c}$ & $56.50 \pm 4.0^{\mathrm{a}, \mathrm{A}}$ & $36.33 \pm 4.8^{b, c}$ & $P<0.001$ & $P<0.001$ & $P<0.001$ \\
\hline Koç 4 & $43.50 \pm 3.5^{a, B}$ & $39.67 \pm 5.2^{a, B, C}$ & $28.00 \pm 4.4^{\mathrm{b}, \mathrm{B}}$ & $19.67 \pm 3.3^{b, B}$ & & & \\
\hline Koç 5 & $49.50 \pm 1.7^{\mathrm{a}, \mathrm{B}}$ & $33.00 \pm 3.9^{b, B}$ & $30.33 \pm 5.0^{b, B}$ & $19.83 \pm 4.0^{\mathrm{c}, \mathrm{B}}$ & & & \\
\hline
\end{tabular}

a,b,c; her satırdaki, A,B,C; her sütundaki farklı üst karakterler istatistiksel olarak farklılığı ifade etmektedir.

Tablo 3. Koç ve Sulandırıcı interaksiyonunun normal spermatozoa oranı üzerine etkisi

\begin{tabular}{|c|c|c|c|c|c|c|c|}
\hline & Yağsız süt tozu & Tris & Andromed & Bioxcell & Koç & Sulandırıcı & Etkileşim \\
\hline Koç 1 & $63.50 \pm 5.43^{\mathrm{B}, \mathrm{D}}$ & $60.17 \pm 6.97^{B}$ & $57.33 \pm 5.99^{A}$ & $59.83 \pm 6.24^{\mathrm{A}}$ & \multirow{5}{*}{$\begin{array}{c}P<0.00 \\
1\end{array}$} & \multirow{5}{*}{$P<0.001$} & \multirow{5}{*}{$P<0.001$} \\
\hline Koç 2 & $77.17 \pm 3.60^{\mathrm{a}, \mathrm{A}}$ & $70.00 \pm 4.34^{\mathrm{a}, \mathrm{b}, \mathrm{A}}$ & $63.83 \pm 3.25^{b, c, A}$ & $58.00 \pm 2.28^{c, A}$ & & & \\
\hline Koç 3 & $63.00 \pm 5.87^{a, D}$ & $51.67 \pm 5.28^{b, c}$ & $63.50 \pm 6.09^{a, A}$ & $52.33 \pm 4.69^{\mathrm{b}, \mathrm{A}}$ & & & \\
\hline Koç 4 & $52.33 \pm 4.59^{a, c}$ & $52.00 \pm 5.97^{a, c}$ & $48.50 \pm 5.43^{a, B}$ & $40.33 \pm 3.98^{b, B}$ & & & \\
\hline Koç 5 & $59.00 \pm 3.90^{a, B, C, D}$ & $45.67 \pm 4.23^{c, c}$ & $43.17 \pm 4.31^{\mathrm{c}, \mathrm{B}}$ & $36.50 \pm 3.27^{b, c, B}$ & & & \\
\hline
\end{tabular}

\section{Tartışma ve Sonuç}

Var olan çalışmada en yüksek çözüm sonu spermatozoa motilitesi yağsız süt tozu sulandırıcısı ile dondurulmuş spermalardan elde edilirken, en düşük spermatozoa motilitesi Bioxcell sulandırıcısı ile dondurulmuş sperma örneklerinden elde edilmiştir. Sulandırıcılar arasında yapılan istatiksel değerlendirmelerde çözüm sonu spermatozoa motilitesi, ölü spermatozoa oranı, anormal spermatozoa oranları yönüyle gruplar arasında kaydedilen farklılıklar önemli $(P<0.001)$ bulundu (Tablo 1). Bu çalışmadaki bulguları destekler nitelikteki sonuçlar Lopez-Saez ve ark. (2000) ile Kulaksız ve ark. (2012) tarafından bildirilmiştir. Paulenz ve ark. (2000) ile Gündoğan (2009) ise süt bazlı sulandırıcı ile tris bazlı sulandırıcıyı karşılaştırdıklarında çözüm sonu spermatozoa motilitesi ve mebran mütünlüğünü en yüksek tris bazlı sulandırıcılar ile dondurulmuş spermalardan elde etmişlerdir. Lymberopoulus ve Khalifa (2010) donmuş spermanın potansiyel fertilizasyonunun korunmasında Bioxcellin Andromed'ten daha üstün rol oynadığını rapor ederlerken, Gil ve ark. (2003) ise Bioxcell'in koç spermasının dondurulmasında kullanılması sonucu elde edilen bulguların yağsız süt tozu sulandırıcısı bulgularından hiç bir farkı olmadığını bildirmişlerdir. Var olan çalışmada ise diğer sulandırıcılar ile karşılaştırıldığında Bioxcell sulandırıcısının çözüm sonu motilitenin sürdürülmesinde kriyoprotektif etkisinin daha az olduğu görüldü. Dorji ve ark. (2014) tarafından yapılan bir çalışmada ise Bioxcell ve tris sulandırıcılarının çözüm sonu sperma kalitesi (motilite, membrane bütünlüğü) üzerine etkileri bakımından herhangi bir farklılık bulamamışlardır. Var olan bu tutarsız 
sonuçlar, kullanılan sperma sulandırıcılarının içeriğinin farklı olmasından kaynaklanabilir. Bilindiği gibi sulandırıcı kompozisyonu başarılı bir sperma dondurma işlemi için önemlidir (Salamon ve Maxwell 2000). Bioxcell sulandırıcısının antioksidanlarla güçlendirilmiş olması, yumurta sarısı bazlı sulandırıcılara göre bir avantaj değildir. Çünkü oksidatif strese karşı spermatozoanın korunmasında etkili olan fosfolipit, kolestorol ve düşük yoğunluklu lipoporteinler yumurta sarısının doğal bileşeni olarak yumurtada bulunmaktadır. Ayrıca kullanılan sulandırıcılar ve teknikler benzer olduğundan dolayı ortaya çıkan farkılı̆̆ı doğrudan çalışmanın yapıldığı, koçların bireysel özelliklerine veya araştırıcılara bağlamak mümkün olabilir. Koç sperması soğuk şokuna karşı çok hassastır ve spermanın dondurulabilirliğinde bireysel farklılıklar var olabilir. Bu çalışmada da koç spermasının dondurulabilirliğinde bireysel farklııklar ortaya çıkmıştır. Bu farklııık o kadar geniş ki, koçların dondurulabilirliği iyi ya da dondurulabilirliği kötü olarak sınıflandırılmasına izin vermektedir (Medrano ve ark., 2002). Spermanın donma ve çözüm sonu tolerasındaki bireysel farklılık daha önceden birçok hayvan türünde rapor edildiğinden dolayı bu farklılı̆ı̆n koçlarda var olması süpriz değildir. (Ros-Santaella ve ark., 2014). Roca (2006) tarafından dondurulmuş spermanın canlılı̆ındaki farkı açıklayan faktörün bireysel fark olduğu belirtilmiştir. Donma ve çözdürmeye karşı spermatozoanın duyarlıı̆ı̆ındaki bireysel fark genetik orjinli olabilir (Ros-Santaella ve ark., 2014). Thurston ve ark. (2002) ile Fraser ve ark. (2008) tarafından dondurulabilirliği kötü olarak ve dondurulabilirliği iyi olarak sınıflandırılan bireyler arasındaki kriyopreservasyona bağlı yaralanmaların ve motilitedeki değişikliğin temelinde genetik faktörün var olduğu belirtilmiştir. Kriyopreservasyona bağı meydana gelen yaralanmalarla ilişkili genetik faktörlerin altında yatan mekanizma tam olarak anlaşılamazken, bu durum koç sperması ile sperma sulandırıcısı içeriğinin interaksiyonu sonucu meydana gelebilir. Plante ve ark. (2015) tarafından ejakulasyonda spermaya eklenen Bağlayıcı spermatozoa protein (BSP)'lerinin sığırlarda süt proteinleriyle etkileşime girdiğini ve süt bazlı sulandırıcılar kullanılmasıyla meydana gelen bu etkileşiminin de spermanın dondurulmasında olumlu etkili yapacağını bildirmişlerdir. BSP proteinlerinin, kolesterol ve fosfolipidleri spermatozoa membranından uzaklaştırarak spermanın komposizyonunun değişmesi ile spermatozoonlar üzerine zararlı etki gösterdiği bildirilmiştir. Plante ve ark. (2015) tarafından BSP proteinleri ile yumurta sarısında bulunan düşük yoğunluklu lipoproteinlerin etkileşimi sonucu sperm membranlarından kolesterol ve fosfolipit ekstraksiyonunun önlendiği ve bu yüzden prezervasyon süresince yumurta sarııının spermatozoayı koruduğunu rapor etmişlerdir. Ayrıca sütten izole edilen kazein taneciklerinin spermatozoa membranları için zararlı etkiye sahip olan BSP proteinleri ile etkileşime girdiği gösterilmiştir. (Plante ve ark., 2015). Daha sonra sığırlarda yapılan bir çalışmada ise BSP proteinlerinin kazein tanecikleri, alfa laktaalbumin ve beta laktoglobulin gibi birçok süt proteinini bağladığı bildirilmiştir. BSP proteinlerinin homologları bizon, teke, aygır, domuz ve koç gibi birçok türde isole edilmiştir. Var olan çalışmada da sulandırıcı kompozisyonu ile koç arasında bir interaksiyonun var olduğu ve koç spermasının dondurulmasında bireysel farklılıklar üzerine süt proteinleri ve yumurta sarısının koruyucu etki yaptığı saptanmıştır.

Sonuç olarak, dondurma ve çözdürme prosedürleri spermatozoanın canlıı̆ı̆ında geniş bir bireysel çeşitliliğe neden olacağından bu teknoloji hala suboptimal olarak dikkate alınmaktadır. Optimize dondurma protokolü bireysel çeşitliliğin azaltılmasına yardımcı olabilir. Süt bazıı sulandırıcılar çözüm sonu sperma kalitesini artırmakta ve koçlar arası bireysel farkı azaltmaktadır. Bu yüzden süt bazlı sulandırıcılar sulandırıcı bireysel koç spermasının dondurulmasında dondurma öncesi bir referans sulandırıcı olarak kullanılabilir.

\section{Kaynaklar}

Barbas JP, Mascarenhas RD, 2009: Cryopreservation of domestic animal sperm cells. Cell Tissue Bank, 10, 49-62.

Dorji P, Pattarajinda V, Vongprolub V, 2014: Cryopreservation of semen of mithun and siri bulls. Bangl J Vet Med, 12, 147-153.

Fraser L, Chandra SP, Strzeżek J, 2008: Identification of amplified fragment length polymorphism markers associated with freezability of boar semen-a preliminary study. Med Weter, 64, 646-649.

Gil J, Rodriguez-Irazoqui M, Lundeheim N, Soderquist L, Rodriguez-Martinez H, 2003: Fertility of ram semen frozen in Bioxcell and used for cervical artificial insemination. Theriogenology, 59, 1157-1170.

Gündoğan M, 2009: Short term preservation of ram semen with different extenders. Kafkas Univ Vet Fak Derg, 15, 429- 435.

Holt WV, 2000: Fundamental aspects on sperm cryobiology: the importance of species and individual differences. Theriogenology, 53, 47-58.

Kulaksiz R, Daşkın A, 2007: Teke spermasının kısa ve uzun surely saklanması. Vet Hek Dern Derg, 78, 4, 51-56.

Kulaksiz R, Çebi Ç, Akçay E, 2012: The effect of different extenders on the motility and morphology of ram sperm frozen or stored at $4{ }^{\circ} \mathrm{C}$. Turk J Vet Anim Sci, 36, 177-182.

Lopez-Saez A, Ortiz N, Gallego L, Gadre JJ, 2000: Liquid storage $\left(5{ }^{\circ} \mathrm{C}\right)$ of ram semen in different diluents. Arch Androl, 44, 155-164. 
Medrano A, Watson PF, Holt WV, 2002: Importance of cooling rate and animal variability for boar sperm cryopreservation: insights from the cryomicroscope. Reproduction, 123, 315-322.

Lymberopoulus AG, Khalifa TA, 2010: Sperm chromatin stability during in vitro manipulation of beef bull semen. Reprod Domest Anim, 45, 2, 307-314.

O'Hara L, Hanrahan JP, Richardson L, Donovan A, Fair S, Evans AC, Lonergan P: 2010: Effect of storage duration, storage temperature, and diluent on the viability and fertility of fresh ram sperm. Theriogenology, 73, 4, 541-549.

Paulenz H, Kommisrud E, Hofmo PO, 2000: Effect of longterm storage at different temperatures on the quality of liquid boar semen. Reprod Domest Anim, 35, 83-87.

Plante G, Luisgnan MF, Lafleur M, Manjunath P, 2015: Intraction of milk proteins and Binder of Sperm (BSP) Proteins from boar, stallion and ram semen. Reprod Biol and Endocrin, 13, 1-13.

Roca J, Hernandez M, Carvajal G, Vazquez JM, Martinez EA, 2006: Factors influencing boar sperm cryosurvival. J Anim Sci, 84, 2692-2699.
Ros-Santaella JL, Dominguez-Rebolledo AE, Grade JJ, 2014: Sperm flagellum volume vetermines freezability in Red Deer spermatozoa. PLOS ONE, 9, 11, 1-11.

Smith JF, Asher GW, Briggs RM, Morrow CJ, Murray GR, Oliver JE, Parr J, Veldhuizen FA, Upreti GC, 1993: Effect of diluent and storage time on pregnancy rate in ewes after intrauterine insemination. Proceedings of the New Zealand Society of Animal Production, 53, 295-298.

Salamon S, Maxwell WM (2000): Storage of ram semen. Anim Reprod Sci, 62, 77-111.

Thurston LM, Siggins K, Mileham AJ, Watson PF, Holt WV, 2002: Identification of amplified restriction fragment length polymorphism markers linked to genes controlling boar sperm viability following cryopreservation. Biol Reprod, 66, 545-554.

Watson PF, 1995: Recent developments and concepts in the cryopreservation of spermatozoa and the assessment of their post-thawing function. Reprod Fertil Dev, 7, 871-891.

*Yazışma Adresi: Çiğdem Çebi ŞEN

Harran Üniversitesi, Veteriner Fakültesi,

Dölerme ve Suni Tohumlama Anabilim Dalı, Şanlıurfa, Türkiye.

e-mail: cigdemcebi@hotmail.com 